\title{
Network Pharmacology-based to Investigate Pharmacological Mechanisms of Active Ingredients in Gegen Qinlian Pill to Ameliorate Irinotecan- induced Diarrhea
}

Research

Keywords:

Posted Date: April 9th, 2021

DOI: https://doi.org/10.21203/rs.3.rs-107306/v2

License: (1) This work is licensed under a Creative Commons Attribution 4.0 International License. Read Full License 


\section{Abstract}

The authors have requested that this preprint be withdrawn due to author disagreement.

\section{Full Text}

The authors have withdrawn this preprint from Research Square. 